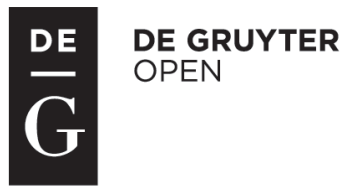

\title{
CHARACTERISTICS OF STAPHYLOCOCCUS XYLOSUS ISOLATED FROM SUBCLINICAL MASTITIS IN COWS*
}

Mariola Bochniarz;, Władysław Wawron, Marek Szczubiał, Piotr Brodzki, Tomasz Piech, Roland Kusy

\author{
Department and Clinic of Animal Reproduction, Faculty of Veterinary Medicine, \\ University of Life Sciences, Głęboka 30, 20-612 Lublin, Poland \\ •Corresponding author: mariolabochniarz@interia.pl
}

\begin{abstract}
The aim of the present study was to determine virulence factors and antibiotic susceptibility of Staphylococcus xylosus isolated from subclinical mastitis in cows. The material consisted of 42 isolates of $S$. xylosus obtained from 276 samples of milk collected from cows with subclinical mastitis. The isolates were obtained from the udder secretions of 33 cows from farms in the Lublin region (Poland). S. xylosus was found in $\mathbf{1 5 . 2 \%}$ of tested milk samples. The study did not reveal any macroscopic changes in the milk or symptoms in the cow's body. The number of somatic cells in milk samples ranged from 245,000 to $416,000 / \mathrm{ml}$ of milk (on average $268,000 / \mathrm{ml}$ of milk). The ability to produce slime was observed in $\mathbf{4 2 . 9 \%}$ of $S$. xylosus isolates. None of the tested isolates demonstrated the ability to produce protease or cause haemolysis. Five isolates of $S$. xylosus $(11.9 \%)$ were classified to the methicillin-resistant group. The mecA gene was not found in any of these isolates. The enzyme $\beta$-lactamase was detected in $28.6 \%$ of $S$. xylosus isolates. The highest efficacy against S. xylosus was demonstrated for cephalosporin antibiotics: cefacetrile and cefoperazone $(80.1 \%$ and $76.2 \%$ of susceptible isolates of $S$. $x y$ losus, respectively). A significant quantity of isolates was resistant to streptomycin, linkomycin, penicillin and neomycin (approximately $10 \%$ of susceptible isolates of $S$. xylosus).
\end{abstract}

Key words: cows, subclinical mastitis, $S$. xylosus

Coagulase-negative staphylococci (CNS) occur widely in the natural environment and colonize both the skin and mucous membranes of animals and people. While they have been regarded for decades as non-pathogenic, they have currently become an etiological factor for cow mastitis in many countries (Honkanen-Buzalski et al., 1994; Myllys et al., 1998; Chaffer et al., 1999; Makovec and Ruegg, 2003; Pitkälä et al., 2004; Rajala-Schultz et al., 2004; Taponen et al., 2007; Malinowski

*Source of financing: WKP/DS-1. 
and Klossowska, 2010). CNS may cause clinical mastitis, but in the majority of cases they cause subclinical form of inflammation (Taponen et al., 2007; Persson Waller et al., 2011). Subclinical infections in individual dairy cattle farms affect 40 to $80 \%$ of cows over the year (Czerw et al., 2007). Cows with subclinical mastitis pose a risk for the entire herd, because the absence of visible external symptoms of inflammation means that this condition remains unnoticed by the owner and untreated for a long period of time. As a result, it leads to development of clinical form of mastitis or the appearance of lesions typical of the chronic process (Aarestrup and Jensen, 1997; Chaffer et al., 1999; Taponen et al., 2006). Management of mastitis caused by CNS is difficult primarily due to the heterogenicity of this group of microorganisms. More than 15 species of coagulase-negative staphylococci have been identified as aetiological factors of mastitis (Thorberg et al., 2009; Persson Waller et al., 2011). The reference literature (Malinowski et al., 2006) and our own research (Bochniarz et al., 2013 a) suggest that $S$. xylosus is often predominant among CNS isolated from cow mastitis.

The aim of the present study was to determine virulence factors and antibiotic susceptibility of Staphylococcus xylosus isolated from subclinical mastitis in cows.

\section{Material and methods}

The study material consisted of 42 isolates of Staphylococcus xylosus from 276 samples of milk collected from cows with subclinical mastitis. The isolates were obtained from the udder secretion of 33 cows from farms located in the Lublin region (Poland). In 24 cows $S$. xylosus was isolated only from one quarter of the udder, while in 9 cows from two udder quarters. The cows with $S$. xylosus belonged to 4 free-stall herds. Clinical examination of cows and macroscopic evaluation of the milk were performed prior to collection of milk samples for bacteriological testing. The cows from which the milk samples were collected were not given any medications in the current lactation.

Bacteriological testing of the milk was carried out in compliance with the generally accepted procedures. Milk samples were brought to room temperature, thoroughly mixed and inoculated on agar medium (BTL, Łódź, Poland) supplemented with sterile, defibrinated sheep blood (5\% of the agar solution volume). After 24 hours of incubation at $37^{\circ} \mathrm{C}$ under aerobic conditions, the microorganisms were initially identified based on the colony morphology, examination of microscopic preparations coloured with the use of the Gram method and the coagulase test. Afterwards, the coagulase-negative staphylococci were identified using the API STAPH commercial test (Biomerieux, France). This test was performed in accordance with the manufacturer's recommendations.

Evaluation of ability to produce haemolysins. A solution of Columbia Agar Base (Oxoid, England) with a concentration of $39 \mathrm{~g}$ in 1 litre of distilled water was sterilized at $121^{\circ} \mathrm{C}$ for 15 minutes. After cooling the medium to $50^{\circ} \mathrm{C}$ it was supplemented with defibrinated sheep blood ( $5 \%$ of the medium solution volume) and 
poured on Petri plates. A Columbia Agar Base medium with the addition of 5\% defibrinated rabbit blood was prepared in the same manner. After consolidation of the medium the CNS strains were inoculated. The plates were incubated for 24 hours at $37^{\circ} \mathrm{C}$. The reference Staphylococcus aureus from the ATCC 25923 collection was used as a positive control.

Evaluation of ability to produce protease. A solution of Nutrient Gelatin (Oxoid, England) with the concentration of $128 \mathrm{~g}$ in 1 litre of distilled water was sterilized at $121^{\circ} \mathrm{C}$ for 15 minutes and spread on Petri plates. After consolidation of the medium the CNS strains were inoculated in the form of a thin line. The plates were incubated for 24 hours at $37^{\circ} \mathrm{C}$. Interpretation of the result: a zone 4 times wider than the CNS strain growth line was considered a positive result. The reference Staphylococcus aureus from the ATCC 25923 collection was used as a positive control.

Evaluation of slime-producing ability. The slime-producing ability of S. xylosus was evaluated by testing adhesion to polystyrene surfaces according to Christensen et al. (1983). Colonies of each tested isolate collected from the solid medium (agar enriched with 5\% sheep blood) were placed in sterile test tubes containing $4 \mathrm{ml}$ tryptic soy broth (TSB) (Oxoid, England). After incubation for $24 \mathrm{~h}$ at $37^{\circ} \mathrm{C}$, the contents of the test tubes were removed by aspiration, washed with distilled water, and stained with crystal violet. A blue film covering the inner surface of the test tube, indicating the presence of slime, was considered to be a positive result.

Slime-producing ability was also tested using Congo Red Agar (Sigma) (Freeman et al., 1989). Overnight cultures in TSB were inoculated onto CRA plates and incubated at $37^{\circ} \mathrm{C}$ for $24 \mathrm{~h}$. Biofilm formation was detected based on the presence of black or nearly black colonies on the agar.

Evaluation of phenotypic resistance of coagulase-negative staphylococci to methicillin. The test was performed with the use of Oxacillin Resistance Screening Agar Base (Oxoid, England) with the addition of ORSAB Selective Supplement. In order to perform the test a medium solution at a concentration of $51.75 \mathrm{~g}$ in $500 \mathrm{ml}$ of distilled water was sterilized at $121^{\circ} \mathrm{C}$ for 15 minutes. One vial of ORSAB Selective Supplement was added to the medium cooled to a temperature of $50^{\circ} \mathrm{C}$ (oxacillin concentration in the solution was $0.5 \mu \mathrm{g} / \mathrm{ml}$ ) and then the result was poured onto Petri plates. The CNS isolates were inoculated after consolidation of the medium. The plates were incubated for $24-48$ hours at $37^{\circ} \mathrm{C}$. The reference Staphylococcus aureus ATCC 25923 was used as a positive control.

Evaluation of genetically conditioned resistance of coagulase-negative staphylococci to methicillin. Isolation of DNA was carried out with the use of the enzymatic digestion method using CTAB. Then the isolated DNA underwent testing with the use of the PCR method in order to determine the presence of the mecA gene. In the amplification reaction, complementary starters were used in the conservative region in the area of the mecA gene, limiting the fragment to a length of $533 \mathrm{bp}$. Starters for the PCR were synthesized in Oligo-PAN in Warsaw (Poland). The following sequences of starters were used for the mecA gene (Louie et al., 2002):

mec1: 5, AAA ATC GAT GGT AAA GGT TGG C 3, mec2: 5, AGT TCT GCA GTA CCG GAT TTG C 3, 
The reaction mixture consisted of: $1 \mathrm{U}$ of Taq Polymerase (Fermentas, Lithuania), $2.5 \mu \mathrm{l}$ of $10 \mathrm{x}$ concentrated buffer for Taq Polymerase, $2.5 \mu \mathrm{l}$ of dNTPs, $1 \mu \mathrm{l}$ of mec1 starter, $1 \mu \mathrm{l}$ of mec2 starter, $3 \mu \mathrm{l}$ of $\mathrm{MgCl}_{2}$, and $9.9 \mu \mathrm{l}$ of distilled water. The amplification products were analysed electrophoretically in 1.5\% agar gel (Sigma, USA) with the addition of the mass standard (100bp DNA, Fermentas, Lithuania).

The tubes were placed in Biometra T3 (Germany) thermal cycler and were heated for $1 \mathrm{~min}$ at $95^{\circ} \mathrm{C}$, followed by a 1 -min denaturation at $94^{\circ} \mathrm{C}, 1-$ min annealing at $55^{\circ} \mathrm{C}$ and elongation for $1 \mathrm{~min}$ at $72^{\circ} \mathrm{C}$. Denaturation, annealing and elongation were repeated for a total of 40 cycles. Next the samples were loaded onto a $1.5 \%$ agarose gel and were electrophoresed for $30 \mathrm{~min}$, stained with ethidium bromide and viewed with UV light. The presence of a 533-bp band was considered a positive result.

Evaluation of capacity of MRCNS to produce $\boldsymbol{\beta}$-lactamase. The determination was carried out using the $\beta$-Lactamase Test (Oxoid, England). The rod tip impregnated with nitrocefin was immersed in the staphylococci colony on a solid agar medium and a small mass of bacterial cells was collected. The result was noted after 5 minutes. The change in the colour of the impregnated stick tip to pink-red was interpreted as a positive result.

Antibiotic susceptibility of microorganisms was evaluated using the discdiffusion method on Mueller-Hinton agar. S. xylosus was examined for sensitivity to the following antibiotics: amoxicillin with clavulanic acid $(30 \mu \mathrm{g})$, ampicillin $(10 \mu \mathrm{g})$, cefacetrile $(30 \mu \mathrm{g})$, cephalexin $(30 \mu \mathrm{g})$, cefoperazone $(75 \mu \mathrm{g})$, ceftiofur $(30 \mu \mathrm{g})$, linkomycin $(15 \mu \mathrm{g})$, neomycin $(30 \mu \mathrm{g})$, penicillin $(10 \mathrm{u})$, streptomycin $(10 \mu \mathrm{g})$ and tetracycline $(30 \mu \mathrm{g})$. Isolates were classified as susceptible or resistant based on species-specific epidemiological cut-off values issued by the European Committee on Antimicrobial Susceptibility Testing (EUCAST) (http: \www.eucast. org).

The types of mastitis were classified according to the standard rules (Gentilini et al., 2002; De Vliegher et al., 2003; Moon et al., 2007) after taking into account the results of the clinical examination of cows, bacteriological test of milk and determination of SCC (somatic cell count) in milk samples with the use of a Fossomatic apparatus (Denmark). SCC $>200000 / \mathrm{ml}$ of milk and the presence of bacteria in bacteriological cultures without general symptoms were considered indicative of subclinical mastitis.

\section{Results}

S. xylosus was found in $15.2 \%$ of tested milk samples. The study did not reveal any macroscopic changes in the milk or symptoms in the cow's body. SCC in milk samples ranged from 245,000 to $416,000 / \mathrm{ml}$ of milk (on average $268,000 / \mathrm{ml}$ of milk).

The test results related to the characteristics responsible for the pathogenicity of S. xylosus isolated from subclinical mastitis are presented in Table 1 . The ability to 
produce slime was observed in 18 isolates of S. xylosus (42.9\%). None of the isolates demonstrated the ability to produce protease or cause haemolysis.

The five isolates of $S$. xylosus (11.9\%) were classified to the methicillin-resistant group (Table 2). The mecA gene was not observed in any of these isolates. The ability to produce $\beta$-lactamase was detected in 12 isolates of S. xylosus $(28.6 \%)$.

The data presented in Table 3 suggest that the most significant effectiveness was demonstrated by antibiotics from the group of cephalosporins: cefacetrile and cefoperazone ( $80.1 \%$ and $76.2 \%$ of susceptible isolates of S. xylosus, respectively). A large percentage of isolates susceptible to amoxicillin with clavulanic acid and ceftiofur (64.3\% and $61.9 \%$ of susceptible isolates, respectively) was also observed. The percentage of $S$. xylosus isolates susceptible to cephalexin, ampicillin and tetracycline was $38.1 \%, 33.3 \%$ and $26.2 \%$, respectively. A large proportion of CNS isolates was resistant to streptomycin, lincomycin, penicillin and neomycin (approximately 10\% of susceptible isolates).

Table 1. Some virulence factors of S. xylosus

\begin{tabular}{l|cc}
\hline \multirow{2}{*}{ Virulence factor } & \multicolumn{2}{|c}{ Staphylococcus xylosus (42) } \\
\cline { 2 - 3 } Slime & No. (\%) of S. xylosus isolates producing virulence factors \\
Proteases & 18 & 42.9 \\
Haemolysins & 0 & 0.0 \\
$\beta$-lactamase & 0 & 0.0 \\
\hline
\end{tabular}

Table 2. Phenotypic resistance to methicillin and mecA gene

\begin{tabular}{l|rr}
\hline \multirow{2}{*}{} & \multicolumn{2}{|c}{ Staphylococcus xylosus (42) } \\
\cline { 2 - 3 } & \multicolumn{2}{|c}{ No. (\%) of S. xylosus isolates } \\
\hline Phenotypic resistance to methicillin & 5 & 11.9 \\
mecA gene & 0 & 0.0 \\
\hline
\end{tabular}

Table 3. Antibiotic susceptibility of S. xylosus

\begin{tabular}{l|cc}
\hline \multirow{2}{*}{\multicolumn{1}{c}{ Antibiotic }} & \multicolumn{2}{c}{ Staphylococcus xylosus (42) } \\
\cline { 2 - 3 } & \multicolumn{2}{c}{ No. (\%) of sensitive isolates } \\
\hline Ampicillin & 14 & 33.3 \\
Amoxicillin with clavulanic acid & 27 & 64.3 \\
Cephalexin & 16 & 38.1 \\
Cefacetrile & 34 & 80.1 \\
Cefoperazone & 32 & 76.2 \\
Ceftiofur & 26 & 61.9 \\
Lincomycin & 5 & 11.9 \\
Neomycin & 4 & 9.5 \\
Penicillin & 4 & 9.5 \\
Streptomycin & 5 & 11.9 \\
Tetracycline & 11 & 26.2 \\
\hline
\end{tabular}




\section{Discussion}

In a previous study (Bochniarz et al., 2013 a), S. xylosus was the most frequently isolated CNS species from cow mastitis. It is worth emphasizing that it was predominant in the clinical forms of mastitis which were accompanied by lesions in udder and macroscopic changes in milk. This result correlated with the data obtained by Malinowski et al. (2006) in the western part of Poland. The authors claim that S. xylosus was the most frequently observed species among CNS isolated from milk samples between 2003 and 2006. S. xylosus has also been isolated by other authors (Jarp, 1991; Birgersson et al., 1992; Davidson et al., 1992; Thorberg et al., 2009).

The reference literature suggests that coagulase-negative staphylococci may cause both transient and persistent udder infections (Taponen et al., 2007). In the study carried out by Thorberg et al. (2009), S. xylosus was one of the CNS species most frequently isolated from mastitis, but the percentage of persistent inflammations caused by this pathogen was below $20 \%$. Similar results were obtained by Taponen et al. (2007).

In the study conducted by Jarp (1991), S. xylosus constituted 7.4\% of all CNS. It was isolated with approximately the same frequency in both clinical and subclinical cases of mastitis. It caused mastitis accompanied by topical lesions in the udder. However, no general symptoms were observed in the cow's body. In the study conducted by Birgersson et al. (1992), a considerably larger percentage of S. xylosus isolates was obtained from clinical and subclinical mastitis $(50.0 \%$ and $38.9 \%$, respectively) than from milk of healthy cows (11.1\% of all S. xylosus isolates). In addition, in this study, a capsule was detected only in 5 of 203 strains of CNS, and 3 of these strains belonged to $S$. xylosus. This suggests that production of a true capsule is probably not a major virulence determinant in the pathogenicity of CNS causing mastitis. However, it shall be stressed that all the encapsulated S. xylosus were isolated from clinical cases of bovine mastitis.

The authors claim that an important role in pathogenesis of mastitis is played by the staphylococcus slime capsule, which enables adherence of bacteria to the tissue surface and production of bacterial biofilm (Aguilar et al., 2001; Lee and Lee, 2006). In the study of Tremblay et al. (2013), S. xylosus had the greatest ability to form biofilms. In the study conducted by Bedidi-Madani et al. (1998), S. xylosus constituted $35.7 \%$ of all CNS producing slime, isolated from the milk of goats. In our own study, production of pseudocapsules was observed in $42.9 \%$ of S. xylosus isolates; whereas, all the isolates of $S$. xylosus were likewise protease-negative and haemolysin-negative during earlier research (Bochniarz and Wawron, 2012), regardless of whether they were isolated from clinical or subclinical mastitis. This correlates with the results obtained by other authors (Birgersson et al., 1992; Devriese et al., 1994).

The common use of antibiotics, mainly of the $\beta$-lactam type, in the treatment of cow mastitis resulted in multi-resistance of the bacteria isolated from milk (Pitkälä et al., 2004; Moon et al., 2007; Persson Waller et al., 2011; Bochniarz et al., 2013 b). In our research, a large percentage of $S$. xylosus isolates was resistant to penicillin, neomycin, lincomycin, tetracycline and ampicillin. Data from the reference literature 
confirm that the number of CNS isolated from different locations and different clinical cases in people and animals, as well as from animal products, has increased and at the same time the number of strains of these staphylococci resistant to antibiotics has also increased (Myllys et al., 1998; Pitkälä et al., 2004). In the study carried out by Gundogan and Ataol (2013), 66.7\% of the S. xylosus isolates obtained from meat, milk and cheese were resistant to at least 2 different antibiotics.

In addition, the number of CNS isolates producing $\beta$-lactamases and isolates with the mecA gene resistant to all the groups of $\beta$-lactam antibiotics has increased recently (Devriese et al., 2002; Gentilini et al., 2002; Moon et al., 2007). In our own study, $\beta$-lactamase was detected in approximately $30 \%$ of S. xylosus isolates. The mecA gene was not observed in any of these isolates, unlike earlier research (Bochniarz et al., 2013 b) in which the presence of this gene was observed in 2 isolates of S. xylosus isolated from the clinical form of mastitis. Analogical results were obtained by Kot et al. (2013). From among 91 strains of S. xylosus, only in two cases did the researchers observe the presence of the mecA gene (1 strain isolated from clinical mastitis and 1 strain from subclinical mastitis).

The results of the study demonstrate that, in spite of the significant variability of features, $S$. xylosus is potentially pathogenic and may cause mastitis with different intensities of clinical symptoms. These infections are often difficult to treat due to the large number of isolates resistant to antibiotics.

\section{References}

A a r e stru p F.M., J e n s e n N.E. (1997). Prevalence and duration of intramammary infection in Danish heifers during the peripartum period. J. Dairy Sci., 80: 307-312.

A guila r B., A moren a B., I t u r r a ld e M. (2001). Effect of slime on adherence of Staphylococcus aureus isolated from bovine and ovine mastitis. Vet. Microbiol., 78: 183-191.

B e d i d i - M a d a n i N., Green l and T., R i c hard Y. (1998). Exoprotein and slime production by coagulase-negative staphylococci isolated from goats' milk. Vet. Microbiol., 59: 139-145.

B irgers s on A., Jons s on P., Holmberg O. (1992). Species identification and some characteristics of coagulase-negative staphylococci isolated from bovine udders. Vet. Microbiol., 31: 181-189.

B o chniarz M., Wawron W. (2012). Haemolytic and proteolytic activity of coagulase-negative staphylococci isolated from mastitis cows. Pol. J. Vet. Sci., 15: 61-65.

B o c h n i a r z M., Wa wr on W., S z c z u b i ał M. (2013 a). Coagulase-negative staphylococci (CNS) as an aetiological factor of mastitis in cows. Pol. J. Vet. Sci., 16: 487-492.

B o chniarz M., Waw ron W., S z c zubiał M. (2013 b). Resistance to methicillin of coagulasenegative staphylococci (CNS) isolated from bovine mastitis. Pol. J. Vet. Sci., 16: 687-692.

Chaffer M., Le itner G., Winkler M., Gli ckman A., Krifuck s O., Ezra E., S a ran A. (1999). Coagulase-negative staphylococci and mammary gland infections in cows. Zentralbl. Veterinarmed. B, 46: 707-712.

Czerw M., Molenda J., Kosek-Paszkowska K., Bystroń J., Kotowicz M. (2007). Comparison of somatic cell count measurement in milk obtained by electronic and microscopic methods (in Polish). Med. Weter., 63: 104-106.

Davidson T.J., D ohoo I.R., Donald A.W., Hariharan H., Collins K. (1992). A cohort study of coagulase negative staphylococcal mastitis in selected dairy herds in Prince Edward Island. Can. J. Vet. Res., 56: 275-280. 
De Vliegher S., Laevens H., Devriese L.A., Opsomer G., Leroy J.L., B arke ma H.W., d e Kruif A. (2003). Prepartum teat apex colonization with Staphylococcus chromogenes in dairy heifers is associated with low somatic cell count in early lactation. Vet. Microbiol., 92: $245-252$.

D e vriese L.A., La even s H., Ha e s e brou ck F. (1994). A simple identification scheme for coagulase negative staphylococci from bovine mastitis. Res. Vet. Sci., 57: 240-244.

Devriese L.A, B a ele M., Van e e chout te M., Martel A., H a e s e brouck F. (2002). Identification and antimicrobial susceptibility of Staphylococcus chromogenes isolated from intramammary infections of dairy cows. Vet. Microbiol., 87: 175-182.

Fre e m a n D.J., F a lk in e r F.R., K e a n e C.T. (1989). New method for detecting slime production by coagulase negative staphylococci. J. Clin. Pathol., 42: 872-874.

Gentilini E., Denamiel G., Betancor A., Rebuelto M., Rodriguez F.M., De Torrest R.A. (2002). Antimicrobial susceptibility of coagulase-negative staphylococci isolated from bovine mastitis in Argentina. J. Dairy Sci., 85: 1913-1917.

Gundogan N., A t a o 1 O. (2013). Biofilm, protease and lipase properties and antibiotic resistance profiles of staphylococci isolated from various foods. Afr. J. Microbiol. Res., 7: 3582-3588.

Honkanen-Buzalski T., Myllys V., Pyörälä S. (1994). Bovine clinical mastitis due to coagulase-negative staphylococci and their susceptibility to antimicrobials. J. Vet. Med. B., 41: $344-350$.

J a r p J. (1991). Classification of coagulase-negative staphylococci isolated from bovine clinical and subclinical mastitis. Vet. Microbiol., 27: 151-158.

Kot B., Piechota M., Wolska K.M., Frankowska A., Zdunek E., Binek T., Kło potowska E., Antosiewicz M. (2013). Phenotypic and genotypic antimicrobial resistance of staphylococci from bovine milk. Pol. J. Vet. Sci., 15: 677-683.

Lee C.Y., Lee J.C. (2006). Staphylococcal capsule. In: Gram-positive pathogens, Fischetti V.A, Novick R.P., Ferretti J.J., Portnoy D.A., Rood J.I. (eds). ASM Press, Washington DC, pp. $456-463$.

Lou i e L., Goodfellow J., Mathieu P., Glatt A., Lou ie M., Simor A.E. (2002). Rapid detection of methicillin-resistant staphylococci from blood culture bottles by using a multiplex PCR assay. J. Clin. Microbiol., 40: 2786-2790.

M a k o ve c J.A., R u e g g P.L. (2003). Results of milk samples submitted for microbiological examination in Wisconsin from 1994 to 2001. J. Dairy Sci., 86: 3466-3472.

Malinowski E., Kłos s ow ska A. (2010). Mastitis caused by coagulase-negative staphylococci in cows. Med. Weter., 66: 89-92.

Malinowski E., Las s a H., Kłoss ow ska A., S mulski S., Markiewicz H., Kaczmarow s k i M. (2006). Etiological agents of dairy cows' mastitis in western part of Poland. Pol. J.Vet. Sci., 9: 191-194.

M o on J.S., L e e A.R., Kang H.M., L e e E.S., K i m M.N., P a ik Y.H., Park Y.H., Joo Y.S., K o o H.C. (2007). Phenotypic and genetic antibiogram of methicillin-resistant staphylococci isolated from bovine mastitis in Korea. J. Dairy Sci., 90: 1176-1185.

Myllys V., Asplund K., Brofeldt E., Hirvela-Koski V., Honkanen-Buzalski T., Junttila J., Kulkas L., Myllykangas O., Niskanen M., Saloniemi H., S andholm M., Saranpaa T. (1998). Bovine mastitis in Finland in 1988 and 1995 - changes in prevalence and antimicrobial resistance. Acta Vet. Scand., 39: 119-126.

Persson Waller K., Aspan A., Nyman A., Persson Y., Grönlund Andersson U. (2011). CNS species and antimicrobial resistance in clinical and subclinical bovine mastitis. Vet. Microbiol., 152: 112-116.

P itkälä A., Haveri M., P y örälä S., Mylly s V., Honkan en - B u zal s ki T. (2004). Bovine mastitis in Finland 2001 - prevalence, distribution of bacteria, and antimicrobial resistance. J. Dairy Sci., 87: 2433-2441.

R a j a l a - S c hultz P.J., S m ith K.L., H o g a n J.S., L ove B.C. (2004). Antimicrobial susceptibility of mastitis pathogens from first lactation and older cows. Vet. Microbiol., 102: 33-42.

Taponen S., S i mojoki H., Haveri M., Lars e n H.D., P y örälä S. (2006). Clinical characteristics and persistence of bovine mastitis caused by different species of coagulase-negative staphylococci identified with API or AFLP. Vet. Microbiol., 115: 199-207. 
Taponen S., Koort J., Bjorkroth J., Saloniemi H., Pyörälä S. (2007). Bovine intramammary infections caused by coagulase-negative staphylococci may persist throughout lactation according to amplified fragment length polymorphism-based analysis. J. Dairy Sci., 90: 3301-3307.

Thorberg B.M., Danielsson-Tham M.L., Emanuelson U., Persson Waller K. (2009). Bovine subclinical mastitis caused by different types of coagulase-negative staphylococci. J. Dairy Sci., 92: 4962-4970.

Tremblay Y.D., Lamarche D., Chever P., Haine D., Messier S., Jacques M. (2013). Characterization of the ability of coagulase-negative staphylococci isolated from the milk of Canadian farms to form biofilms. J. Dairy Sci., 96: 234-246.

Received: 4 IV 2014

Accepted: 30 V 2014 